\title{
PROFIL TABIR SURYA EKSTRAK DAN FRAKSI DAUN PIDADA MERAH (Sonneratia caseolaris L.)
}

\author{
Siti Hasanah, Islamudin Ahmad, Laode Rijai \\ Laboratorium Penelitian dan Pengembangan FARMAKA TROPIS \\ Fakultas Farmasi Universitas Mulawarman, Samarinda, Kalimantan Timur \\ Email: sitihasanah960@gmail.com
}

\begin{abstract}
ABSTRAK
Telah dilakukan uji aktivitas tabir surya ekstrak dan fraksi daun pidada merah secara in vitro untuk mengetahui profil tabir surya ekstrak dan fraksi daun pidada merah. Profil tabir surya diketahui dengan metode analisis data berdasarkan hasil pengujian aktivitas tabir surya dengan menggunakan spektrofotometer UV-Vis. Pengujian aktivitas tabir surya ekstrak daun pidada merah didasarkan pada kemampuan ekstrak daun pidada merah mengabsorbsi sinar ultraviolet selanjutnya dilakukan perhitungan persentase transmisi eritema dan pigmentasi kemudian dikategorikan kedalam penilaian aktivitas tabir surya. Hasil penelitian menunjukkan profil tabir surya ekstrak dan fraksi daun pidada merah memiliki aktivitas tabir surya sebagai fast tanning, suntan standar, proteksi ekstra, dan sunblock.
\end{abstract}

Kata kunci: spektrofotometer UV-Vis, daun pidada merah, persentase transmisi eritema, persentase transmisi pigmentasi, profil tabir surya.

\begin{abstract}
Extract and fractions of Sonneratia caseolaris L. Leaves has been the test of sunscreen activity in vitro to determine the sunscreen profile from extract and fractions of Sonneratia caseolaris L. leaves. Sunscreen profile was determine by data analysis method based on the result from testing the sunscreen activity by using UV-Vis spectrophotometer. The test of sunscreen activity of the extract of pidada merah leaves is based on the ability of the sample to absorb ultraviolet light. The absorbance then performed to the calculation of percentage of transmission erythema and pigmentation, and then categorized into the sunscreen activity assessment. The result showed that the sunscreen profile of extract and fractions of leaves of pidada merah has the activity as fast tanning, suntan standard, extra protection, and sunblock.
\end{abstract}

Keywords: UV-Vis spectrophotometer, Sonneratia caseolaris leaves, percentage of erythema transmission, percentage of pigmentation transmission, sunscreen profile.

\section{PENDAHULUAN}

Sinar matahari, disatu pihak memiliki efek yang menguntungkan dan sangat diperlukan oleh mahluk hidup sebagai sumber energi, penyehat kulit dan tulang, misalnya dalam pembentukan vitamin $\mathrm{D}$ dan pro-vitamin yang mencegah penyakit polio atau riketsia, 
tetapi di lain pihak sinar matahari memiliki efek yang merugikan, sinar matahari mengandung sinar UV yang dapat membahayakan kulit. Sinar UV ini dapat menimbulkan berbagai kelainan pada kulit mulai dari kemerahan (eritema), noda hitam (pigmentasi), penuan dini, kekeringan, keriput, bahkan menyebabkan kanker kulit [1]. Dari seluruh radiasi sinar matahari hanya $0,2 \%$ yang menimbulkan reaksi eritema pada kulit, yaitu spektrum sinar UV-B (290$320 \mathrm{~nm}$ ), sedangkan spektrum sinar UVA yang menimbulkan pigmentasi adalah sinar dengan panjang gelombang 320$400 \mathrm{~nm}$. Spektrum sinar UV-C dengan panjang gelombang kurang dari $295 \mathrm{~nm}$ yang mematikan atau disebut spektrum germicidal tidak sampai ke bumi karena tersaring oleh ozon pada lapisan atmosfer [2].

Untuk mencegah semua bahaya yang ditimbulkan oleh sinar matahari, sangatlah penting menggunakan tabir surya yaitu bahan-bahan kosmetik yang secara fisik atau kimia dapat menghambat penetrasi sinar UV ke dalam kulit. Produk tabir surya yang mengandung bahan kimia sintesis telah banyak dikembangkan akhir-akhir ini, akan tetapi masyarakat banyak beralih ke bahan alam yang dianggap lebih aman dan harganya terjangkau.

Tanaman pidada merah (Sonneratia caseolaris L.) adalah salah satu bahan alam yang digunakan secara tradisional, khususnya masyarakat kalimantan pada bagian daunnya dimanfaatkan sebagai salah satu komposisi bedak dingin dan digunakan dengan cara ditempelkan pada wajah ketika sedang beraktivitas dibawah paparan sinar matahari dalam waktu yang cukup lama. Berdasarkan penelitian Afriana [3] menyatakan bahwa daun pidada merah memiliki memiliki aktivitas antioksidan dengan kandungan metabolit sekundernya yaitu senyawa fenolik, flavonoid, saponin, karatenoid dan tanin. Penggunaan zat-zat yang bersifat antioksidan dapat mencegah bebbagai penyakit yang ditimbulkan oleh radiasi sinar UV, beberapa golongan senyawa aktif antioksidan seperti flavonoid telah dilaporkan bahwa memilki kemampuan sebagai perlindungan terhadap sinar UV [4]. Senyawa fenolik khususnya golongan flavonoid mempunyai potensi sebagai tabir surya karena adanya gugus kromofor (ikatan rangkap tunggal terkonjugasi) yang mampu menyerap sinar UV baik UV A 320- $400 \mathrm{~nm}$ maupun UV B (290-320 nm) sehingga mengurangi intensitasnya pada kulit [5]. Sehingga daun pidada merah memungkinkan memiliki profil tabir surya yang potensial sebagai bahan kosmetik terkait tabir surya.

\section{METODE PENELITIAN}

\section{BAHAN}

Bahan yang digunakan: simplisia daun pidada merah, aquadest, pelarut metanol, $n$-butanol, etil asetat dan n-heksan.

\section{PERALATAN}

Alat-alat yang digunakan: seperangkat alat gelas yang terdapat di laboratorium, rotary evaporator (BUCHI), spektrofotometri UV-Vis double beam (Dynamica Halo DB-20S), dan timbangan analitik.

\section{PROSEDUR}

\section{Pengambilan Sampel}

Daun pidada merah yang segar diperoleh di daerah pinggir tepian sungai mahakam samarinda. Daun pidada merah segar sebanyak $2,5 \mathrm{~kg}$ dikeringkan di ruangan terbuka tanpa terpapar sinar matahari secara langsung. Sampel yang digunakan berupa simplisia daun pidada merah. 


\section{Ekstraksi dan Fraksinasi}

Simplisia daun pidada merah dimasukan kedalam wadah maserasi menggunakan pelarut metanol selama 3 hari dan diulangi sebanyak 3 kali. filtrat yang terkumpul dipekatkan dengan rotary evaporator kemudian dilanjutkan di atas tangas air hingga diperoleh ekstrak kental metanol.

Ekstrak kental metanol ditambah aquadest, lalu difraksinasikan dengan pelarut n-heksan, etil asetat dan nbutanol. Masing-masing fraksi kemudian dipekatkan dengan rotary evaporator dan didapatkan fraksi kental fraksi n-heksan, etil asetat dan n-butanol.

\section{Pengujian Aktivitas Tabir Surya}

Larutan sampel dibuat dalam metanol dengan konsentrasi $50 \mathrm{ppm}$ hingga 400 ppm, masing-masing konsentrasi terdiri dari tiga replikasi dan diukur serapannya dengan menggunakan spektrofotometer UV-Vis pada panjang gelombang 292,5-372,5 nm dengan interval $5 \mathrm{~nm}$. Dari nilai serapan yang diperoleh dari tiga replikasi dihitung nilai persen nilai transmisi $(\mathrm{T})$ dengan rumus: $\mathrm{A}=-\log \mathrm{T}$. Nilai transmisi eritema dihitung dengan cara mengalikan nilai transmisi ( $\mathrm{T}$ ) dengan faktor efektivitas eritema $(\mathrm{Fe})$ pada panjang gelombang 292,5-372,5 nm. Nilai transmisi pigmentasi dihitung dengan cara mengalikan nilai transmisi (T) dengan faktor efektivitas pigmentasi (Fp) pada panjang gelombang 322,5-372,5 $\mathrm{nm}$. Selanjutnya nilai persen transmisi eritema dan nilai persen transmisi pigmentasi dihitung berdasarkan rumus \% Transmisi eritema $=\Sigma \mathrm{T} . \mathrm{Fe} / \Sigma \mathrm{Fe}$ dan $\%$ Transmisi pigmentasi $=\Sigma$ T.Fp $/ \Sigma$ Fp (Cumpelik, 1972).

\section{Penentuan Profil Tabir Surya}

Data nilai \% Te dan \% Tp yang diperoleh dari hasil pengujian aktivitas tabir surya dikategorikan kedalam aktivitas tabir surya (Tabel 1).

Tabel 1. Kategori Penilaian Aktivitas Tabir Surya [6]

\begin{tabular}{ccc}
\hline Kategori & $\% \mathrm{Te}$ & $\% \mathrm{Tp}$ \\
\hline Sunblock & $<1$ & $3-40$ \\
Proteksi ekstra & $1-6$ & $42-86$ \\
Suntan standar & $6-12$ & $45-86$ \\
Fast tanning & $10-18$ & $45-86$ \\
\hline
\end{tabular}

\section{HASIL DAN PEMBAHASAN}

Profil tabir surya adalah pengkategorian aktivitas tabir surya yang menyatakan potensi proteksi kulit terhadap sinar matahari pada radiasi UV A (320-400 nm) dan UV B (290-320 nm) yang dimanfaatkan sebagai bahan kosmetik terkait tabir surya. Penentuan profil tabir surya dilakukan dengan metode analisis data yaitu menggunakan data-data absorbansi berdasarkan hasil pengujian aktivitas tabir surya ekstrak kasar dan ekstrak fraksi daun pidada merah secara in vitro dengan menggunakan metode spektrofotometer UV-Vis. Aktivitas tabir surya didasarkan pada kemampuan sampel mengabsorbsi sinar ultraviolet pada panjang gelombang 292,5 nm-372,5 nm. Setelah diperoleh nilai absorbansi (A) tiap $5 \mathrm{~nm}$ pada panjang gelombang 292,5-372,5 $\mathrm{nm}$ yang merupakan panjang gelombang yang dapat menyebabkan eritema dan pigmentasi, maka dapat diketahui nilai transmisi (T) untuk dilakukan perhitungan \%Te dan \%Tp. Semakin kecil nilai trasmisi (T) maka semakin 
baik dikarenakan sinar UV yang diteruskan kedalam kulit semakin sedikit. Kemudian nilai \% Te dan \% Tp dikategorikan ke dalam penilaian aktivitas tabir surya yaitu sunblock, proteksi ekstrak, suntan standar atau fast tanning.

Berdasarkan hasil penelitian daun pidada merah dapat diketahui profil tabir surya ekstrak dan fraksi daun pidada merah dalam berbagai variasi konsentrasi (Tabel 2), menunjukan bahwa peningkatan konsentrasi ekstrak disertai dengan peningkatan efek penyerapan sinar UV sehingga semakin kecil nilai persentase transmisi eritema maupun nilai persentase transmisi pigmentasinya.

Tabel 2. Profil Tabir Surya Sampel

\begin{tabular}{cccccc}
\hline Sampel & $\begin{array}{c}\text { Konsentrasi } \\
(\mathrm{ppm})\end{array}$ & $\% \mathrm{Te}$ & Kategori & $\% \mathrm{Tp}$ & Kategori \\
\hline Ekstrak kasar & 50 & 17,12 & - & 13,05 & Sunblock \\
& 75 & 17,12 & Fast tanning & 13,05 & Sunblock \\
& 100 & 10,05 & Suntan standar & 6,88 & Sunblock \\
& 150 & 3,45 & Proteksi ekstra & 1,92 & Sunblock \\
& 200 & 1,25 & Proteksi ekstra & 0,57 & Sunblock \\
Fraksi $n$-heksan & 250 & 0,49 & Sunblock & 0,19 & Sunblock \\
& 100 & 10,51 & - & 9,15 & Sunblock \\
& 125 & 10,51 & Fast tanning & 9,15 & Sunblock \\
& 150 & 9,32 & Suntan standar & 7,69 & Sunblock \\
& 200 & 4,32 & Proteksi ekstra & 3,32 & Sunblock \\
Fraksi etil & 300 & 1,05 & Proteksi ekstra & 0,72 & Sunblock \\
asetat & 400 & 0,23 & Sunblock & 0,14 & Sunblock \\
& 25 & 14,34 & - & 6,04 & Sunblock \\
& 50 & 14,34 & Fast tanning & 6,04 & Sunblock \\
& 75 & 7,39 & Suntan standar & 2,27 & Sunblock \\
& 100 & 3,96 & Proteksi ekstra & 0,79 & Sunblock \\
& 150 & 1,43 & Proteksi ekstra & 0,19 & Sunblock \\
& 200 & 0,66 & Sunblock & 0,13 & Sunblock \\
Fraksi $n$ - & 75 & 5,30 & - & 3,52 & Sunblock \\
butanol & 100 & 5,30 & Proteksi ekstra & 3,52 & Sunblock \\
& 150 & 3,22 & Proteksi ekstra & 2,51 & Sunblock \\
& 200 & 2,28 & Proteksi ekstra & 1,34 & Sunblock \\
& 250 & 0,94 & Sunblock & 0,50 & Sunblock \\
& 300 & 0,46 & Sunblock & 0,22 & Sunblock \\
\hline
\end{tabular}

Nilai persentase transmisi pigmentasi (\% $\mathrm{Tp}$ ) adalah nilai yang menggambarkan kemampuan suatu molekul kimia untuk memproteksi kulit dari sinar UV yang dapat menyebabkan pigmentasi yaitu banyaknya jumlah energi sinar UV yang diteruskan pada radiasi UV A (322,5-372,5 $\mathrm{nm})$. Pigmentasi adalah perubahan warna kulit yang lebih gelap akibat pajanan UV dapat teramati dalam waktu 24 jam dan puncaknya pada hari ke 8. Pigmentasi tertunda ini akibat peningkatan produksi pigmen melanin dan menyebabkan peningkatan ketebalan epidermis. Hasil yang diperoleh menunjukan bahwa ekstrak dan fraksi daun pidada merah pada konsentrasi 50 ppm hingga 400 ppm 
dapat memproteksi secara total terhadap sinar UV A.

Nilai persentase transmisi eritema $(\% \quad \mathrm{Te})$ adalah nilai yang menggambarkan kemampuan suatu molekul kimia untuk memproteksi kulit dari sinar UV yang dapat menyebabkan eritema yaitu banyaknya jumlah energi sinar UV yang diteruskan pada radiasi UV B (292,5-337,5). Eritema adalah kemerah-merahan pada kulit yaitu proses inflamasi yang terjadi 2-3 jam setelah sengatan surya, berkembang dalam 10-24 jam akibat dari kerusakan sel yang menyebabkan terlepasnya zat mirip/histamin, sehingga terjadi pelebaran pembuluh darah dan eritema. Hasil yang diperoleh menujukan bahwa ekstrak dan fraksi daun pidada merah hanya pada konsentrasi tertentu yang dapat memproteksi secara total sinar UV B sedangkan konsentrasi lainnya masih dapat meneruskan sinar UV B.

\section{Tabir Surya Sunblock}

Sunblock adalah aktivitas tabir surya yang paling terbaik, berdasarkan Wilkinson [7] menyatakan sunblock adalah kemampuan suatu molekul kimia yang dapat memberikan perlindungan maksimum terhadap radiasi sinar UV pada kulit dalam bentuk penghalang fisik dan memproteksi secara total untuk kulit yang sangat sensitif terhadap sinar UV A $(322,5-372,5 \mathrm{~nm})$ dan UV B (292,5$337,5)$ mencegah terjadinya eritema dan pigmentasi.

$\begin{array}{ccc}\text { Hasil yang } & \text { diperoleh } \\ \text { berdasarkan nilai persen } & \text { transmisi }\end{array}$ eritema menunjukan bahwa pada konsentrasi 250 ppm ekstrak kasar metanol, konsentrasi 400 ppm fraksi nheksan, konsentrasi 200 ppm fraksi etil asetat dan konsentrasi 250 ppm fraksi nbutanol memilki aktivitas tabir surya sebagai sunblock.

\section{Tabir Surya Proteksi Ekstra}

Proteksi ekstra adalah kemampuan suatu molekul kimia tabir surya yang melindungi kulit yang bersifat sensitif dari sinar UV untuk mencegah terjadinya pigmentasi dan eritema dengan mengabsorbsi kurang dari $95 \%$ radiasi UV B yang masih dapat meneruskan 1$6 \%$ sinar UV B [3].

Hasil yang diperoleh berdasarkan nilai persen transmisi eritema menunjukan bahwa pada konsentrasi 150-200 ppm ekstrak kasar metanol, konsentasi 200-300 ppm fraksi n-heksan, konsentrasi 100-150 ppm fraksi etil asetat dan konsentrasi 100-200 ppm fraksi n-butanol memiliki aktivitas tabir surya sebagai proteksi ekstra.

\section{Tabir Surya Suntan Standar}

Suntan standar adalah kemampuan suatu molekul kimia tabir surya yang melindungi kulit yang bersifat normal atau kulit yang tidak sensitif tehadap sinar UV dan merupakan tabir surya yang dapat menggelapkan kulit dengan mengabsorbsi $85 \%$ atau lebih radiasi UV B yang akan menghasilkan sedikit eritema tanpa rasa sakit [7].

Hasil yang diperoleh berdasarkan nilai persen transmisi eritema menunjukan bahwa pada konsentrasi 100 ppm ekstrak kasar metanol, konsentrasi 150 ppm fraksi nheksan dan konsentrasi 75 ppm fraksi etil asetat memiliki aktivitas tabir surya sebagai suntan standar.

\section{Tabir Surya Fast Tanning}

Fast tanning adalah kemampuan suatu molekul kimia tabir surya yang dapat menggelapkan kulit secara cepat tanpa menimbulkan eritema dengan mampu memberikan transmisi penuh pada radiasi UV A untuk memberikan efek penggelapan yang maksimal [3].

Hasil yang diperoleh berdasarkan nilai persen transmisi eritema menunjukan bahwa pada konsentrasi 75 ppm ekstrak kasar metanol, konsentrasi 125 ppm fraksi nheksan dan konsentrasi 50 ppm fraksi etil 
asetat memiliki aktivitas tabir surya sebagai fast tanning.

Profil tabir surya fraksi etil asetat yang paling baik dibandingkan dengan sampel ekstrak dan fraksi lainnya, dikarenakan fraksi etil asetat pada konsentrasi 200 ppm memiliki aktivitas sebagai sunblock, pada konsentrasi 100 ppm memiliki aktivitas sebagai proteksi ekstra, pada konsentrasi 75 ppm memiliki aktivitas sebagai suntan standard dan pada konsentrasi 50 ppm memiliki aktivitas sebagai fast tanning yang merupakan konsentrasi yang lebih kecil dibandingkan dengan ekstrak dan fraksi lainnya sehingga dapat dikatakan bahwa fraksi etil asetat sangat potensial dimanfaatkan sebagai bahan aktif kosmetik terkait tabir surya.

Fraksi etil asetat memilki aktivitas paling baik untuk menyerap sinar UV tidak terlepas dari kemampuan pelarut etil asetat menarik kandungan kimia dari daun pidada merah. Hal ini sesuai dengan Wungkana [8] yang menyatakan bahwa fraksi etil asetat memilki aktivitas tabir surya yang paling terbaik dikarenakan sifat kepolaran dari etil asetat yang bersifat semi polar sehingga lebih banyak melarutkan senyawa fenolik yang bersifat polar yang merupakan golongan flavonoid. flavonoid merupakan senyawa fenol yang berpotensi sebagai tabir surya karena dapat menyerap sinar UV. Butanol yang bersifat polar memilki gugus $\mathrm{C}_{4} \mathrm{H}_{9}$ berperan sebagai senyawa non polar, dengan adanya gugus tersebut membuat butanol lebih non polar dibandingkan dengan metanol dan senyawa polar tetap tinggal dan larut kedalam pelarut etil asetat. Sedangkan fraksi n-heksan memiliki aktivitas tabir surya yang paling rendah dibandingkan dengan sampel lainnya, hal ini dikarenakan fraksi nheksan melarutkan senyawa yang bersifat non polar seperti minyak-minyak yang terdapat dalam daun pidada merah sedangkan senyawa fenolik bersifat polar.

\section{KESIMPULAN}

Berdasarkan hasil penelitian yang dilakukan maka dapat disimpulkan bahwa profil tabir surya sampel daun pidada merah yang memiliki aktivitas tabir surya yang paling baik adalah fraksi etil asetat dibandingkan dengan ekstrak dan fraksi lainnya.

\section{DAFTAR PUSTAKA}

1. Tranggono, R.I. 2007. Buku Pegangan Ilmu Pengetahuan Kosmetik. Jakarta: PT. Gramedia Pustaka

2. Cumpelik, B. S., 1972, Analitical Procedures and Evaluation of Sunscreens. Journal of the Society of Cosmetics Chemistry Vol. 25 No. 3.

3. Afriana, M. F. 2013. Bioaktivitas dan Aktivitas Ekstrak Daun Pidada Merah (Sonneratia caseolaris L.) Terhadap Artemia Salina Leach. Samarinda: Fakultas Farmasi Universitas Mulawarman.

4. Hogade, M.G., Basawaraj, S.P., dan Dhumal, P. 2010. Comparative Sun Protection Factor Determination of Fresh Fruits Extract of Cucumber VS Marketed Cosmetic Formulation. Journal of Pharmaceutical, Biological and Chemical Sciences

5. Wolf, R., Wolf, D., Morganti, P., Ruocco, V. 2001. Sunscreen, Clinics in Dermatology :252- 459.

6. Balsam, M. S., \& Sagarin, E. 1972. Cosmetics: Science and Technology $2^{\text {nd }}$ Ed., Vols. 1-3. Interscience Publishers, Inc: New York.

7. Wilkinson, J. B dan Moore, R. J., 1982, Harry's Cosmeticology ( $7^{\text {th }}$ edition). Chemical Publishing Company. New York.

8. Wungkana, I. 2013. Aktivitas Antioksidan Dan Tabir Surya Fraksi Fenolik Dari Limbah Tongkol Jagung (Zea mays L.). Jurnal Ilmiah Farmasi UNSRAT Vol. 2 No. 04 